\title{
Design Study on Gas Turbine High Temperature Reactor (GTHTR300)
}

\author{
Kazuhiko Kunitomi ${ }^{1)}$, Xinglong Yan $^{1)}$, Yukio Tachibana ${ }^{2)}$, Akio Saikusa ${ }^{2)}$, Shusaku Shiozawa ${ }^{\text {) }}$ \\ 1) Department of Advanced Nuclear Heat Technology, Oarai Research Establishment, Japan Atomic Energy Research \\ Institute, Ibaraki, JAPAN \\ 2) Department of HTTR Project, Oarai Research Establishment, Japan Atomic Energy Research Institute, Ibaraki, JAPAN
}

\begin{abstract}
JAERI (Japan Atomic Energy Research Institute) has undertaken the study of an original design concept of gas turbine high temperature reactor, the GTHTR300 (Gas Turbine High Temperature Reactor 300). The general concept of this study is development of a greatly simplified design that leads to substantially reduced technical and cost requirements for earlier technology deployment. Newly proposed design features on reactor core and gas turbine units enable the GTHTR300 to be an efficient and economically competitive reactor in $2010 \mathrm{~s}$. In the fist phase of the core design, the four-year operation without a refueling was achieved by efficient use of replaceable burnable poisons under the condition that excess reactivity does not exceed $2.5 \% \Delta \mathrm{k} / \mathrm{k}$ during the operation. The value of $2.5 \%$ is conservatively determined based on prevention of severe core damage in an all control withdrawal accident.
\end{abstract}

This paper describes the original design features in detail, exemplified by safety, a particular core and plant design.

\section{INTORODUCTION}

Development of the high-temperature gas-cooled reactor (HTGR) has revived in many countries after a major setback in Germany that had led the HTGR development since 1960s. Especially in South Africa, the commercial reactor project, the PBMR (Pebble Bed Modular Reactor )[1] is under way. Also, various practical design works have been performed in the Netherlands[2], Russia/USA[3] and China[4]. In Japan, development of the HTGR technology has been conducted for over 20 years, and the HTTR (High Temperature Engineering Test Reactor) with outlet gas temperature of $950^{\circ} \mathrm{C}$ and thermal power of $30 \mathrm{MW}$ was constructed at Oarai research establishment in JAERI. Its first criticality was attained in 1998[5] and its full power operation will be carried out in the first half of 2001. Operational data for establishing and upgrading the HTGR technology basis will be accumulated in the next several years.

In parallel to the development and successful operation of the HTTR, JAERI has undertaken the study of an original design concept of gas turbine high temperature reactor, the GTHTR300[6]. The GTHTR300 fully based on the HTTR experience[7] and design studies on future generation HTGR in Japan[8] is expected to be the effective energy source in $2010 \mathrm{~s}$. A detailed investigation on core and plant design will be carried out from the pure economical point of view, and redundancy will be eliminated. In addition, basic technologies concerning a gas-turbine system will be established in various R\&D.

Prior to the detailed study, a core and plant design concept of the GTHTR300 was proposed and roughly evaluated. The GTHTR300 consisting of a block type core has several advantages such as high thermal power and low pressure drop in the core comparing with those of a pebble bed type core. There are the important factors to improve plant efficiency and economy. On the other hand, a major drawback of the block-type core is that it takes at least a few months to reload all fuels using a off-load refueling machine. In contrast, on-load refueling is available in the pebble bed type core although a refueling mechanism is more complicated than that of the block type core. In the new core design, the possibility of a refueling interval extending the maximum six years was investigated by installing replaceable burnable poisons (RBP) around the core. Due to the RBP, plant availability of the GTHTR has the possibility to become more than $90 \%$, and excess reactivity is kept lower than $2.5 \% \Delta \mathrm{k} / \mathrm{k}$ during the operation. A burnup control by the RBP is a big advantage from the standpoint of safety, maintenance, safe guard, amount of waste disposals as well as economy.

Regarding the plant design, non-intercooled cycle was adopted for its simplicity, easy maintenance and cost advantage. In the plant layout, outlet helium gas from a compressor cools the Reactor Pressure Vessel (RPV) to keep its temperature lower than the temperature limit of existing low cost steel SA533. In previous designs, low cost steel' cannot be available because outlet helium gas of $550^{\circ} \mathrm{C}$ from a recuperator flows upward along the inner surface of the RPV. The SA533 steel has large cost advantage against new high temperature resistance material such as $9 \mathrm{Cr}-1 \mathrm{Mo}$ steel.

In the next chapters, such original design features are described in detail, exemplified by safety, the reactor core design and particular plant design. In addition, a schedule of design studies on the GTHTR300 and R\&D for turbomachinery is briefly described.

\section{BASIC PHILOSOPHY OF GTHTR300}

Simplicity and economy are the primary concern. That does not mean that safety is the second concern. Higher level of safety than a current Light Water Reactor (LWR), the so-called severe accident free, is also our goal. A target for electricity cost is $4 \mathrm{Yen} / \mathrm{kWh}$ that is by almost two yen cheaper than that of a typical LWR in Japan. In order to reduce the capital, fuel and operation and maintenance (O\&M) cost, innovative designs are adopted for the GTHTR300. The followings are major items.

1. The highest power not to lose inherent safety 
2. High burn up (average $120 \mathrm{GWd}$ /ton), long refueling cycle (the maximum six years) and low amount of waste disposals

3. Air cooling spent fuel storage

4. Conventional steel vessel for reactor pressure vessel

5. Non-intercooled cycle

6. Stand alone gas turbine generator

7. Horizontal gas turbine generator installation

User requirement for the GTHTR300 was determined with the help of utilities such as Tokyo Electric Power Company (TEPCO) and The Japan Atomic Power Company (JAPCO), and industries such as Mitsubishi Heavy Industries (MHI) and Fuji Electric (FE). Table 1 shows the user requirement for the GTHTR300. The major specifications of the GTHTR300 shown in Table 2 were determined to meet the user requirement.

\section{Table 1 User requirement for the GTHTR300}

Safety goal

Site condition

Seismic condition

Fuel cycle

Nuclear proliferation

Radiation protection

Radioactive waste disposal

Power level

Life time

Availability

Inspection

Inspection period

Economy

Reactor power

Outlet gas temperature

Efficiency

Reactor core

Fuel cycle

type

enrichment

burnup

Safety system refueling

Turbomachinery

Reactor pressure vessel

Radioactive nuclide retention
Radioactive nuclides release shall be prevented by complete passive systems

Meet the site evaluation requirement for a current LWR Additionally, site evacuation shall not be necessary.

replacement of LWR site or new site

the same as that of a next generation LWR

once though, fuel burnup more than $100 \mathrm{GWd} /$ ton

High amount of weapon grade Pu shall not be produced

$0.5 \mathrm{manSv} / \mathrm{ry}$

Liquid $\quad 1 / 10$ of the latest LWR

Solid reuse of fuel blocks if possible

100-4000MWe/site

modular type 100-300MWe/unit

60 years

More than $90 \%$

once/ 2 years

less than 30 days

Capital $40-50$ billion yen/unit (160-200 thousand Yen $/ \mathrm{kWe}$ )

Electric $4 \mathrm{Yen} / \mathrm{kWh}$

Table 2 Major specifications of the GTHTR300

$600 \mathrm{MWth} /$ unit $\times 4$ units

$850^{\circ} \mathrm{C}$

$45.4 \%$

Block type

LEU once through cycle

$\mathrm{UO}_{2}$ coated fuel particle

less than $20 \%$

average $120 \mathrm{GWd} /$ ton

once $/ 6$ years

No active emergency cooling

Horizontal orientation

Mn-Mo steel

Confinement

\section{SAFETY OF GTHTR300}

\section{Defense-in-Depth and severe accident free}

Defense-in-Depth is a basic philosophy for the GTHTR300 as well as a LWR. Various layers of requirement dre used to keep safety. However, there are major differences between the GTHTR300 and the LWR philosophy. The LWR uses highly reliable, redundant and diverse passive or active safety layers. On the other hand, the GTHTR300 safety shall be kept due to inherent safety characteristics and potentially safe components.

Severe accidents are defined as any conditions beyond design-base accidents, causing core damages with fission product releases to the environment, although all severe accident sequences are very low in probability. The new safety philosophy is to avoid most accidents, and to achieve a probability of severe accidents at least two orders lower than current reactors. Even in the worst event, fuel temperature exceeding its failure limit and excessive fuel oxidation by air ingress can be avoided because of inherent safety features and the passive decay heat removal system.

\section{Demonstrable safety}

Nearly full-scale worst accident simulation tests can be carried out to obtain licensing before commercial operations because safety assessment by analysis is not usually enough to convince the public and the regulators of trusting this safety concept. In current reactors no accident simulation tests are carried out before commercial operations although inspection and performance tests in normal condition are conducted. On the other hand, safety demonstration by accident simulation 
tests can, and shall be, requisite to obtain licensing in the GTHTR300.

\section{Mechanistic source term}

Mechanistic source term is used to estimate radionuclide releases for plant siting evaluation instead of non-mechanistic source term based on AEC document TID-14844, Japanese LWR or HTTR safety evaluation guideline.

Initial failure of coated fuel particles in the HTTR in manufacturing is only $8 \times 10^{-5}$ although $10^{-2}$ in design, and no apparent failure was found in continuous irradiation tests up to 6.5\% FIMA at Japan Material Testing Reactor (JMTR). A post irradiation test is also planed to be carried out next year. In addition to these tests, data for long term integrity of the fuel, lift off and plate out behavior will be accumulated in the HTTR operation. Up to date, the 20 MW operation of the HTTR was already finished, and no additional failure was found evidently. These are the reason why the mechanistic source term can be used for the plant siting evaluation.

\section{No containment vessel}

When the above mentioned mechanistic source term is used for the plant siting evaluation, the effective dose equivalent to whole body in the worst event can meet the dose guideline without the containment vessel. No containment vessel is necessary in the GTHTR300 due to salient fuel performance, and resuspension and transport phenomena pertaining to the radionuclide within a primary circuit.

\section{No need for offsite emergency evacuation and no damage on all offsite assets}

Offsite emergency evacuation is not necessary in the worst event selected for the plant siting evaluation. Furthermore, all offsite assets are kept intact and ensured.

\section{PSA and Event selections for the safety evaluation}

Full-scale PSA will not be forced for designing the GTHTR300. It will be used for the selection of postulated events. The categorization of the events to be evaluated is the followings, abnormal conditions " Anticipated operational occurrences (AOO)" and the events beyond AOO "Design basis accidents (DBA)". In addition to these traditional categories, the postulated severest event shall be evaluated among all beyond design basis accident (BDBA). An event with complete loss of forced coolant (depressurization accident) and simultaneous withdrawal of all control rods is selected among all very unlikely events such as anticipated transients without scram (ATWS), station blackout and multiple operator errors. The same worst event is used for the plant site evaluation. The frequency range for AOO, DBA and BDBA is approximately $10^{-2}$ per plant-year, $10^{-4}$ per year and more than $10^{-7}$ per year, respectively. The PSA and engineering judgment is necessary to select these events.

\section{PLANT DESIGN OF GTHTR300}

\section{Conventional steel vessel}

A key technology simplification made in the GTHTR 300 is a reactor pressure vessel (RPV) that can be fabricated of code certified, low-cost steel SA 533/SA508. This is made possible by a newly-conceived plant flow scheme (see Figure 1) in which coolant is circulated through reactor via a pair of leveled coaxial cross duct, thereby exposing the RPV, and all other vessels to temperature below the design limit and at which the behavior of the materials under irradiation is well understood. Use of SA533/SA508 should also drive down the cost per vessel by a large margin. As a result, despite the three vessel count, the overall vessel system is estimated to still cost less than potential vessel system designs of less vessel count but having to use high-temperature, more costly steels such $21 / 4 \mathrm{Cr}-\mathrm{Mo}$ and $9 \mathrm{Cr}-1 \mathrm{Mo}-\mathrm{V}$. The latter has yet been certified for reactor vessel construction. The large saving in material and ease fabrication transportation and erection of the vessels of greatly reduced size contribute to the cost advantage of the present vessel system design.

\section{Plant layout design}

The plant design consists of three subsystem modules, the 600MWt prismatic core reactor, the stand-alone GTG and a heat exchanger, ITX. The three modules are contained in individual vessels and allocated to separate silos. Partitioning the large into properly sized subsystems and arranging them separately proves essential to effectuating and modular construction and maintenance. In the present design the three modules can be factory built and site erected essentially in parallel, with all necessary piping connected when construction is completed. The maintenance can be greatly simplified. The ability to not only construct but also service the plant in truly modular manner will positively impact the economy of the technology.

\section{Non-intercooled design}

The non-intercooled cycle loses plant total efficiency about $2 \%$ comparing with the intercooled cycle. However, it saves the capital cost almost 5\%[9] based on 92 DOE evaluation. When the capital cost is normally assumed to be two thirds of the electricity cost, the non-intercooled cycle gains approximately $3.3 \%$ for the electricity cost. The cost estimation has relatively high margin of errors, and it may be dangerous to evaluate the electricity cost based on roughly determined design specifications. However, if the intercooler is adopted, all water related problems happened in Fort. St. Vrain in USA and AVR in Germany would be happened in the GTHTR300. In the HTTR operation, nitrogen gas used for pressurizing water was stagnated in an air cooler, and deteriorated thermal performance of the air cooler. Besides the operational complexity, a sophisticated inspecting machine is necessary since heat transfer tubes composing the primary boundary in the intercooler shall be inspected according to a Japanese regulation. That makes the O\&M cost higher. Considering all effects, the non-intercooled design superior to the intercooled design. 


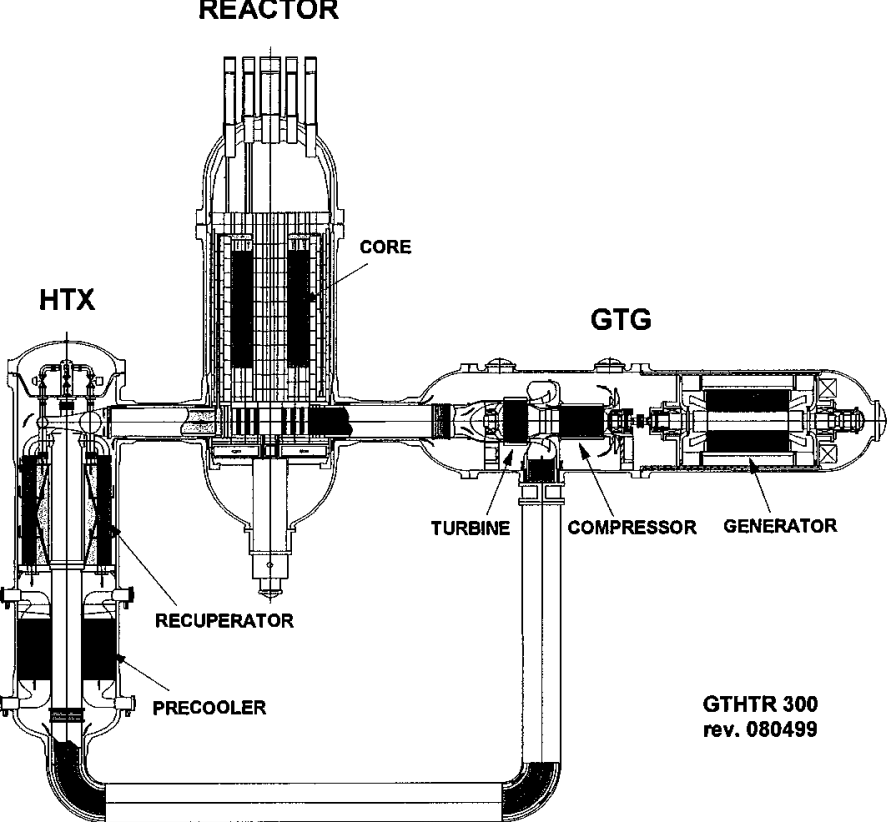

Figure 1 Plant layout of GTHTR300

\section{REACTOR CORE DESIGN OF GTHTR300}

In the severe accident free concept, the maximum fuel temperature during a depressurization accident characterized by a primary pipe rupture plus possible reactivity insertion shall be lower than the temperature limit of $1600^{\circ} \mathrm{C}$. Even in this worst accident, the reactivity insertion shall be limited to lower than $2.5 \% \Delta \mathrm{k} / \mathrm{k}$ when withdrawal of all control rods is postulated as the worst accident. On the other hand, in the case that this design limitation for the excess reactivity is adopted, the reactor cannot be operated without refueling because of lack of the excess reactivity. On-load refueling is not possible because it needs an innovative refueling machine available at the high temperature condition.

Figure 2 shows the change in the excess reactivity during the operation. A six-year operation without refueling needs the excess reactivity of $45 \% \Delta \mathrm{k} / \mathrm{k}$ at the beginning of the core. The previously proposed way in which burnable poisons

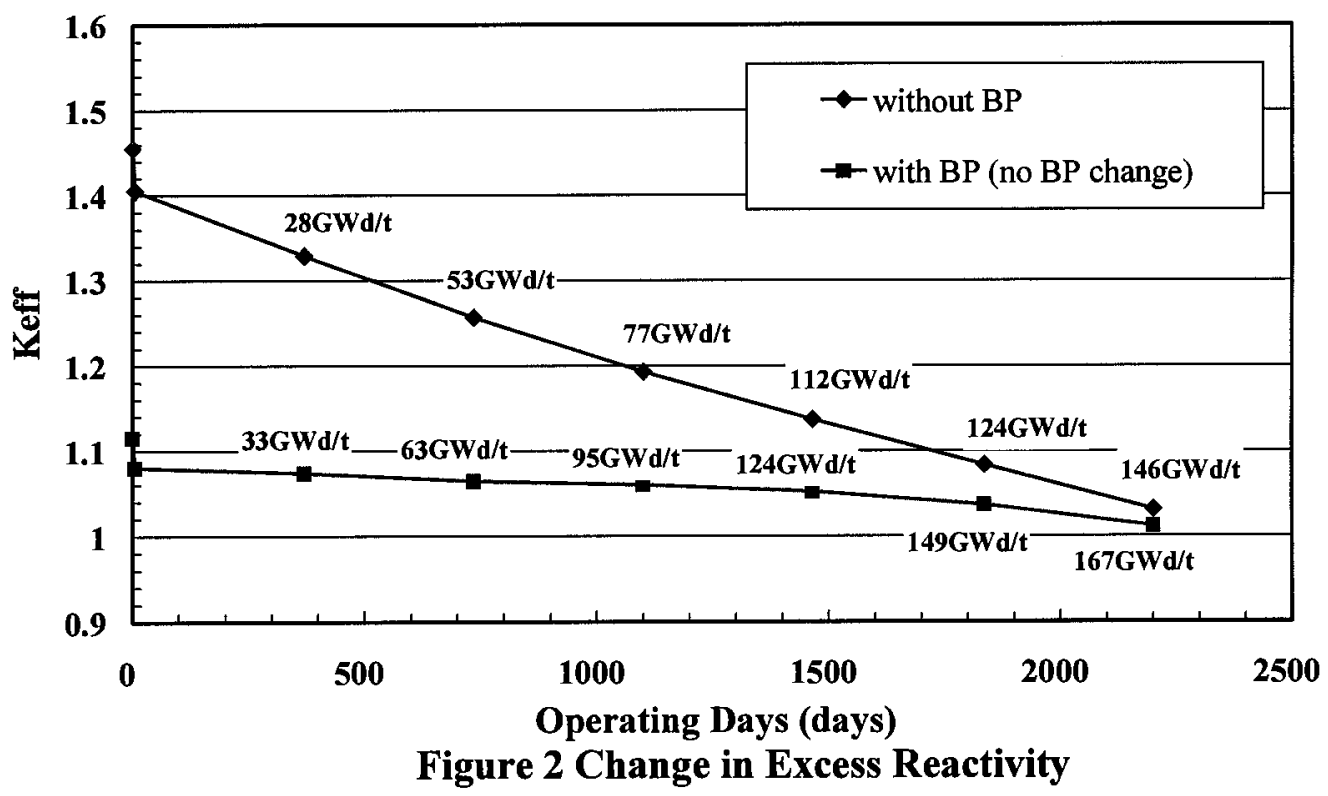


(BP) are installed in fuel blocks reduced the excess reactivity at the beginning of the core to $11 \% \Delta \mathrm{k} / \mathrm{k}$. However, it is still more than four times higher than the limit excess reactivity of $2.5 \% \Delta \mathrm{k} / \mathrm{k}$. The peak excess reactivity during the operation is limited but kept relatively high enough to operate the reactor for the maximum six years. To meet this inconsistent requirement, the newly proposed way uses replaceable burnable poisons (RBP) around the reactor core and its replacement every two years.

Figure 3 shows the design concept using the RBP. The excess reactivity recovers by the replacement of the burnable poison every two years and does not exceed the upper limit since the proper amount of burnable poisons are still placed in the core. This concept was proved by the calculation. The CITATION[10] was used to evaluate the excess reactivity. The white circles show the calculated reactivity considering the replacement of the RBP. This analysis proved that the excess reactivity is maintained the reasonable level for operation but not so high for four years.

The four-year operation with the reactivity of less than $2.5 \% \Delta \mathrm{k} / \mathrm{k}$ was achieved by the RBP. When the single rod withdrawal is postulated as the worst accident, the six-year operation is possible. However, the RBP is not efficient considering neutron economy, and the four-year operation is not enough for a economical perspective. In the detailed evaluation to be performed next year, the other way not fully dependent on the RBP will be investigated for reducing the initial and remaining enrichment.

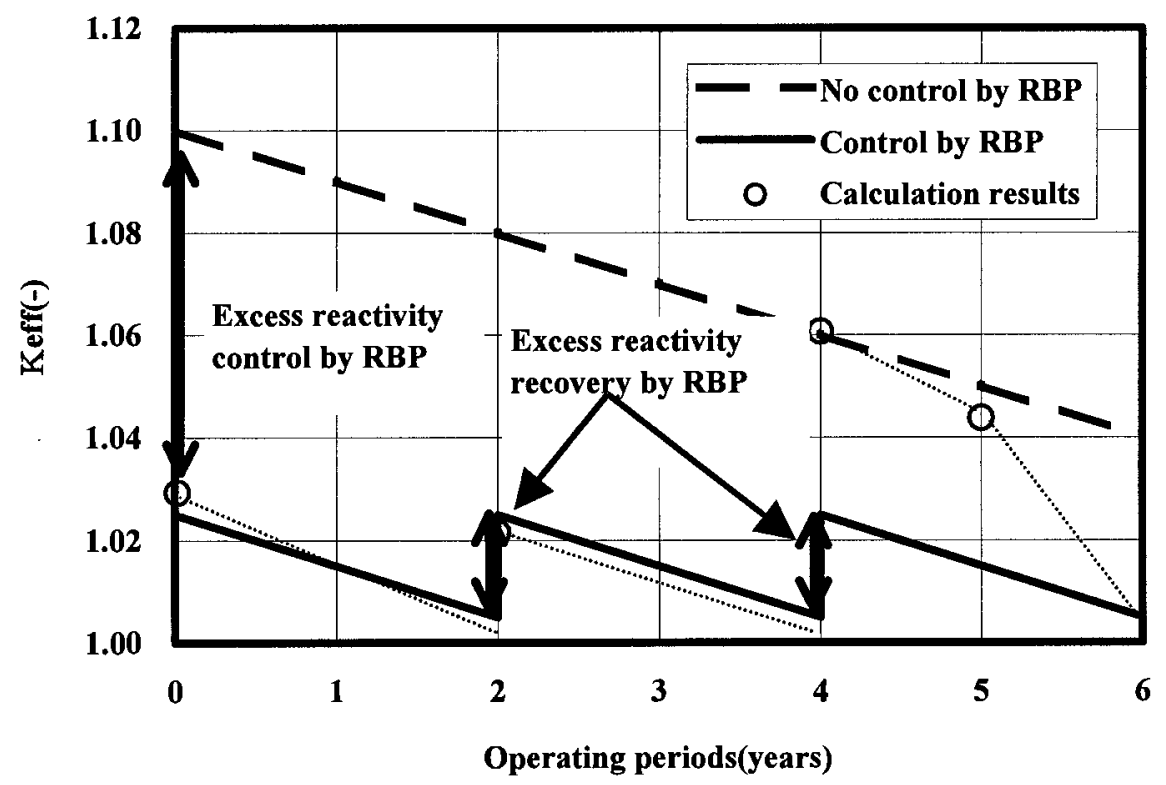

Figure 3 Excess reactivity control by burnable poison

\section{DEVELOPMENT ITEMS AND SCHEDULE FOR THE GTHTR300}

Table 3 shows the development items and schedule for the GTHTR300. The detailed design phase will start in FY-2001 and it takes three years. The final economical target for the GTHTR300 is 4 Yen/kWh. Every innovative and sophisticated idea will be accepted, and every redundancy will be eliminated. As for the R\&D, the development of a compressor and magnetic bearing for the gas turbine system will start in FY-2001. These are key components for this plant and still have technical uncertainties such as aero dynamics in the compressor and control performance of the magnetic bearing.

Check \& Review on the design by a special board consisting of members from utilities, universities, industries and the other national research laboratories will be performed every three or four months so that our design can meet the requirement from private sectors especially utilities.

In addition to above development in Japan, a control and operational performance test using $1 / 3$ scale whole gas turbine system is scheduled to be carried out in accordance with the JEARI-MINATOM cooperation. A gas turbine test section will be connected the existing high temperature helium gas loop at OKBM in Russia.

All the developments will be finished at the end of FY-2007. Then the next development concerning commercial reactors will be delegated to private sectors. 
Table 3 Development items and schedule

\begin{tabular}{|c|c|c|c|c|c|c|c|}
\hline Items $\quad$ Year & 2001 & 2002 & 2003 & 2004 & 2005 & 2006 & 2007 \\
\hline Design study & & & & & & & \\
\hline R\&D & & & & & & & \\
\hline Compressor & & & & & & & \\
\hline Magnetic bearing & & & & & & & \\
\hline International testing & & & & & & & \\
\hline
\end{tabular}

\section{SUMMARY}

The basic concept of the GTHTR300 has been determined in this study. Some of new concepts proposed here will produce great advantage in terms of economy. In the next fiscal year, Japanese GTHTR 300 project will enter the detailed design stage. In the reactor core design, further investigation for the new long fuel cycles attracting utilities will start. In the plant design, the detailed design of a compressor, turbine, recuperator, etc. will be carried out. We expect that the GHHTR300 will be the new innovative energy source in $2010 \mathrm{~s}$.

\section{REFERENCE}

1. Nicholls D. R., "Utility Requirements for HTGRs", Proc. Technical Committee Mtg. High Temperature Gas Cooled Reactor Technology Development, Commercializing the HTGR, Johannesburg, Republic of South Africa, November 13-15, 1996, International Atomic Energy Agency.

2. Van Heek A. I., "Status of the HTR-Programme in the Netherlands", Proc. Workshop of the Role of Modular HTRs in Netherlands, Petten, The Netherlands, November 28-30, 1994, p.83(1994).

3. Simon W. A. and Shenoy A. S., "International cooperation in developing the GT-MHR evolution and program status", Proc. of an IAEA Technical Committee Meeting, Petten, the Netherlands, 10-12 November 1997, P67-80.

4. Xu. Y. and Zuo K., "Studies on High temperature Research Reactor in China",. Proc. of the sixth Asian symposium on research reactors", Oarai Research Establishment, Japan, March 29-31, 1999, p9-16.

5. Fujimoto N., Nakano M., Nojiri N., Takeuchi S., Fujisaki K., and Yamashita k., "First criticality prediction of the HTTR by 1/M interposition method", Proc. of the sixth Asian symposium on research reactors", Oarai Research Establishment, Japan, March 29-31, 1999, p328-333.

6. Yan X., Shiozawa S., Kunitomi. K., Muto Y., Miyamoto Y. and Takada S., "Design innovations in GTHTR 300 gas turbine high temperature reactor", Proc. of ICONE 8, Baltimore, USA, April 2-6, 2000.

7. Saito S., " Design of High Temperature Engineering Test Reactor (HTTR)", JAERI 1332, Japan Atomic Energy Research Institute, 1994.

8. Kunitomi K., Tachibana Y., Saikusa S. and Sawa K., "Conceptual design of a 50MW severe-accident-free HTR and the related test program of the HTTR", Nuclear. Technology, Vol. 123, 1998, p245-258.

9. Yan X., private communication

10. Harada H. and Yamashita K., "The reactor core analysis code CITATION 1000P for high temperature engineering test reactor", JAERI-M 89-135, Japan Atomic Research Institute, 1989 (in Japanese). 